\title{
La misión de Carlos Baraibar en Marruecos durante la guerra civil ${ }^{1}$
}

\author{
Miguel antonio Luna Alonso
}

\begin{abstract}
RESUMEN
ABSTRACT

A partir de la documentación hallada

From the documentation found in the en el Archivo del Ministerio de Asuntos Ministry of Foreign Affairs Records (Madrid), Republic Series, on the Exteriores (Madrid), Serie República, procedente en su mayoría de los agentes consulares de España en el Protectorado de Francia en Marruecos $y$ otros funcionarios ciel Ministerio de

Estado, este artículo aporta numerosos detalles inéditos del conocido intento de levantar las cabilas de la zona española de Marruecos que Largo Caballero encargó a Carlos Baraibar, y una interpretación hipotética en clave de política interna que define tal intento como una maniobra de Largo para permanecer en el Gobierno ante el acoso comunista.

PALABRAS CLAVE whole coming Spanish consular agents in French Morocco and other official of Ministry of State, this article provides a number of unpublished data about known attempt for raising the cabilas of Spanish Morocco that Largo Caballero entrusted to Carlos Baraibar, and an hypothetical interpretation in interior policy key that defines such attempt as a trick of Largo to remain in the Government under communist pressure.

KEY WORDS Morocco. Spanish Civil War. Diplomacy. PSOE. PCE.

Marruecos. Guerra civil española.

Diplomacia. PSOE. PCE.
\end{abstract}

1 Este artículo es un extracto del trabajo de investigación inscrito en los cursos de doctorado e inédito La Misión Baraibar: El proyecto del gobierno republicano de levantar las cabilas del Protectorado de España en Marruecos durante la Guerra Civil, visto desde el Ministerio de Estado (Madrid, UNED, 2001). 
Son numerosas las menciones que vienen acumulándose en la bibliografía al fallido intento gubernamental republicano, capitaneado por el periodista, diputado socialista y fiel colaborador de Largo Caballero, Carlos Baraibar Espandaburu, de levantar las cabilas de la zona española del Protectorado en Marruecos controlada por los rebeldes, en mayo de $1937^{2}$.

En el Archivo del Ministerio de Asuntos Exteriores de Madrid, Serie República (AMAE. RE.), conocido como Archivo de Barcelona ${ }^{3}$, hallé abundante documentación al respecto que permite completar y aclarar con numerosos detalles las menciones citadas, como mostraré en la primera parte de este artículo ${ }^{4}$. Dado que la misión de Carlos Baraibar en Marruecos (que denomino Misión Baraibar), delegado directo del Presidente del Consejo de Ministros al frente de una amplia delegación cívico-militar, provocó el enfrentamiento con los agentes consulares en la zona francesa del Protectorado desde donde se preparó, encabezados por el Cónsul General de España en Rabat, Fernando González Arnao, y que la documentación citada procede mayoritariamente del Ministerio de Estado, departamento al que estos pertenecían; la interpretación y correlación de los nuevos detalles de la misión que proporciono, y que abordo en la segunda parte del artículo, es necesariamente incompleta y se limita a una hipótesis razonada que otorga el protagonismo principal de los hechos al contexto político republicano, capitalizado por el enfrentamiento entre caballeristas y comunistas en el seno gubernamental ${ }^{5}$.

2 Madariaga, H. R. de: Los moros que trajo Franco..., Barcelona. Martínez Roca, 2002, p. 425-33. Howson, G., Armas para España (Barcelona, Península, 2000), pág. 108. PAZ, A., La cuestión de Marruecos y la República Española (Madrid, Fundación de Estudios Libertarios Anselmo Lorenzo, 2000), págs. 162-171 y 186 y ss. ALPERT, M., Aguas peligrosas. Nueva Historia internacional de la Guerra Civil Española (Madrid, Akal, 1998), pág. 132. CASANova, M., La Diplomacia española durante la Guerra Civil (Madrid, Ministerio de Asuntos Exteriores, 1996), págs. 83-4. Cierva, R. DE LA, Historia esencial de la Guerra Civil Española (Madridejos, TO, Fénix, 1996), pág. 603. Bolloten, B., La Guerra Civil española: Revolución y contrarrevolución (Madrid, Alianza, 1989), pág. 710. Aróstegui, J. y otros, La Guerra Civil Española. 50 años después (Barcelona, Labor, 1986, 2. ${ }^{a}$ ed.), pág. 89. ThomAs, H., La Guerra Civil Española. 1936-1939 (Barcelona-etc., 1985, 9. ${ }^{2}$ ed.), págs. 628 y 715. ZugAZAGolTIA, J., Guerra y vicisitudes de los españoles (Barcelona, Crítica, 1977, 3. ${ }^{a}$ ed.), pág. 241

3 Pérez Vera, M. (prolog.): Archivo de Barcelona. Inventarios. Ministerio de Estado: 19361939 (Madrid, Ministerio de Asuntos Exteriores, 1991), pág. 9.

4 Intenté vaciar sistemáticamente la contenida en la sección Archivo Reservado (Cajas RE. 431 ), base de la investigación, junto con otros documentos de otras secciones que tendré oportunidad de citar más adelante.

5 La mayor parte de la documentación relevante para la investigación que procede del citado Archivo Reservado, está constituida por informes del propio Arnao al Ministro de Estado; la mayoría, a su vez, remitidos con posterioridad a los hechos relativos a la Misión Baraibar que narra. Otro documento esencial para la investigación lo constituyen los pliegos AMAE. RE. Caja 40, Carpeta 107, Pliegos 2, 3 y 4, que agrupé en lo que sostengo que es un borrador del informe que elaboraron dos altos funcionarios del Ministerio de Estado sobre la Misión Baraibar y la actuación en 


\section{LA MISIÓN BARAIBAR}

El 18 de julio de 1936 un golpe de estado militar provocó el estallido de la Guerra Civil española. El Ejército de África, destacado en el Protectorado de España en Marruecos, cuya función política desempeñaba nuestro país junto con Francia desde 1912, pronto controló allí totalmente la situación y su traslado a la península ofreció a los sublevados una ventaja cualitativa notable en el curso de la guerra. Era, con mucho, el cuerpo mejor preparado y dotado del Ejército español; además, disponía de una cantera inagotable de aguerridos mercenarios en los marroquíes.

Entre los elementos gubernamentales republicanos y antifascistas que apoyaban al Gobierno republicano pronto surgieron iniciativas para intentar acabar con aquella situación tan desfavorable en África o, cuando menos, entorpecer el control de los sublevados para intentar enjugar tan importante desventaja. Algunos elementos socialistas y comunistas españoles en Tánger, estaban en contacto con algunos marroquíes notables de la zona occidental del Protectorado español; entre otros con Dris el Riffi, ex-Bajá de Arcila y Tetuán, a pesar de que gozaba de muy poco crédito entre españoles y marroquíes (a los que había traicionado alternativamente a lo largo de su vida), y franceses ${ }^{6}$.

Hacia finales del mes de noviembre de 1936, llegó a Valencia una representación de estos antifascistas españoles residentes en Tánger, entre los que figuraba Rafael Jiménez Cazorla, militante socialista y miembro del Cuerpo de Telégrafos, que Baraibar iba a utilizar como lugarteniente de su confianza en Marruecos, en vez de a los agentes consulares. Se entrevistaron con algunos miembros del Gobierno y del PCE, y les informaron sobre las posibilidades que a su juicio existían para organizar una sublevación en la zona occidental del Protectorado español en Marruecos. Pocos días después se celebró una reunión a la que asistieron los ministros de Estado y de Agricultura, Julio Álvarez del Vayo y Vicente Uribe, respectivamente; el Subsecretario de la Presidencia, Rodolfo Llopis; el diputado comunista por Granada Antonio Pretel; y el citado Jiménez Cazorla entre otros. En ella expuso Pretel el plan que consideraba necesario realizar en Marruecos y que consistía esencialmente en el desarrollo de

\footnotetext{
ella de delegados gubernamentales y agentes consulares, hasta octubre de 1937, que en gran parte determinó que se encaminara a su previsible final definitivo.

6 AMAE. RE. Caja 40, Carpeta 107, Pliego 2, Folio 570 (en adelante AMAE. RE. 40, 107, 2, 570) y AMAE. RE. 40, 107, 4, 627. ALPERT, M., op. cit., pág. 132. PANDO, J., Historia Secreta de Annual (Madrid, Temas de Hoy, 1999, 4. ${ }^{\circ}$ ed.), pág. 66.
} 
una actividad de propaganda y agitación y en la realización de actos de sabotaje para producir en la zona española del Protectorado marroquí un estado de desasosiego y de intranquilidad que la hiciera terreno abonado para llevar posteriormente a cabo un plan de sublevación. En la misma reunión se le encomendó al PCE el estudio del problema y la formulación del plan concreto correspondiente, para lo cual el mismo Pretel, con algunos colaboradores, salió hacia Marruecos en el mes de diciembre de 1936, donde instaló, con los escasos fondos de que pudo disponer, una emisora de radio clandestina y se puso en contacto con elementos antifascistas de Argelia, con todos los cónsules de la zona francesa del Protectorado y con personas destacadas del Frente Popular francés, muy especialmente con el diputado socialista Lamoureux. Tras haber estudiado sobre el terreno todas las posibilidades y determinado la cantidad aproximada que podría ser precisa para llevar a cabo el proyecto, Pretel salió para Valencia el 31 de diciembre de 1936, en compañía del Cónsul General en Rabat y de Lamoureux, quien, si en Valencia se aceptaba la propuesta de Pretel, marcharía a París para intentar sopesar el ánimo de Léon Blum sobre el particular, pues se estimaba imprescindible contar previamente con la anuencia de las autoridades francesas. Álvarez del Vayo les puso en contacto con Carlos Baraibar, quien en las conversaciones que sostuvieron aquellos días no parecía compartir los criterios de Pretel y, en efecto, el plan fue desestimado aduciendo razones técnicas; aunque la verdadera razón era que Largo Caballero quería impedir la intervención de los comunistas en el asunto, y ya tenía previsto que se encargara de él Baraibar en exclusiva ${ }^{7}$.

Apenas repuesto de una enfermedad que le había tenido postrado, Baraibar telegrafió a Cazorla a Tánger para que viniera a Valencia a preparar el viaje inminente a Marruecos que tenía previsto, con objeto de estudiar sobre el terreno las posibilidades que pudiera haber de agitar las cabilas de la zona española. Cazorla manifestó que era preciso que la persona o delegación que se enviara dispusiera de amplios poderes otorgados por el Presidente del Consejo, a fin de que el Cónsul General de Rabat no pudiera entorpecer la gestión. Estaba prevenido contra Arnao, de quien se había formado un juicio poco favorable, en parte por pertenecer a la antigua carrera diplomática y en parte por las conversaciones mantenidas con él con motivo de la presencia del diputado Pretel en Marruecos. Baraibar, de acuerdo con ello, solicitó y obtuvo del Presidente del Consejo de Ministros una credencial en la que se le conferían plenas facultades para el

AMAE. RE. 40, 107, 2, 572 y 40, 107, 3, 610 . 
cumplimiento de la misión. Con ella, Baraibar llegó a la zona francesa de Marruecos a mediados de febrero, acompañado por Jiménez Cazorla, el Comandante del Cuerpo de Seguridad y Asalto Antonio Moreno Navarro y su esposa, y el Teniente Coronel de Estado Mayor Juan Ayza Borgoñós. Baraibar se entrevistó en Rabat con el Cónsul General, al que dio cuenta, sin revelarle todos los detalles, del asunto que le traía a Marruecos. Después salió para Tánger y, a su regreso a la zona francesa, marchó a Marrakech, donde pasó dos días informándose de la situación en Ifni. En Tánger se entrevistó con Dris el Riffi; y en Marrakech con el Cónsul, Antonio Emilio Monleón de la Lluvia, donde además reclutó a un hermano de éste, José Monleón, telegrafista. Mientras, el Comandante Moreno y su esposa, y el Teniente Coronel Ayza, recabaron también información en un recorrido por diversas ciudades de la zona francesa. Correspondiendo a la desconfianza que Cazorla mostraba hacia él, el Cónsul General dispuso una estrecha vigilancia de las actividades de esta delegación militar, camuflada de forma poco convincente con la presencia de la señora.

Cuando Baraibar se encontraba en Marrakech recibió su nombramiento como Subsecretario de la Guerra y la orden de regresar inmediatamente a Valencia, lo que hizo la madrugada del 23 de febrero desde Casablanca. Esta precipitada salida de Marruecos le impidió convocar a una reunión, que tenía el propósito de celebrar, al Cónsul General en Orán, J. Gomariz, y a los cónsules en Fez y Uxda, Luis Monguió y José María Burgos, respectivamente, para reunir la más amplia información posible sobre la zona española de Marruecos. Por ello Baraibar rogó a Arnao que reuniera en Rabat a Cazorla con los citados cónsules. La reunión tuvo lugar en el Consulado General de Rabat el 25 de febrero de 1937, y en ella se trataron las posibilidades de levantar las cabilas de la zona española del Protectorado, respecto a lo que los cónsules se mostraron pesimistas, pero confiados, por contra, en que sí se podría llevar a cabo una labor de agitación, que incluiría, incluso, acciones de sabotaje, que podrían alterar seriamente el plácido control que ejercían las autoridades rebeldes. Ante estas manifestaciones, junto con las de que los cónsules tenían contactos con algunos notables marroquíes, Cazorla expresó la opinión de que había que coordinar esos contactos aislados con los citados notables, a través de uno de ellos, de reconocido prestigio. Se pusieron de manifiesto los diferentes puntos de vista de delegados y diplomáticos sobre la dirección de las operaciones. Cazorla era partidario, naturalmente, de que la desempeñara la delegación de la que formaba parte y en ese momento dirigía, al margen de los consulados, con los que se contaría únicamente para realizar gestiones políticas ante la Residencia General francesa; los cónsules de que se centralizara en el Consulado 
General en Rabat, prescindiendo incluso de que viniera ningún delegado de España que, sin duda, llamaría la atención, perjudicando la preparación de los planes. Cazorla marchó a Valencia y expuso ante los subsecretarios de la Presidencia y de la Guerra, Llopis y Baraibar, el resultado de la reunión de Rabat ${ }^{8}$.

Con toda esta información se elaboró el plan definitivo que Baraibar fue a ultimar a Marruecos a mediados de abril. Para ello instaló en Casablanca, con la aquiescencia del nuevo cónsul en aquella ciudad, Antonio Monleón, anterior cónsul en Marrakech, una delegación cívico-militar para el desarrollo de la misión. Dirigiría la parte civil Cazorla, con la participación de Dris el Riffi, al que Baraibar entregó dos de los cuatro millones y medio de francos de que habría dispuesto para la misión (además de un coche nuevo), para que preparara la sublevación de los cabilas de la zona española con sus contactos en ella ${ }^{9}$. La delegación militar añadió a los ya citados Moreno y Ayza, al Capitán del Cuerpo de Seguridad y Asalto Inocente Fernández Ordóñez y al Comandante de Caballería Eladio Rodríguez Cañivano, residente en Agadir, con la misión de sublevar las cabilas de Ifni, y que estaría en contacto con la delegación a través del citado telegrafista José Monleón, instalado en Marrakech. La misión de la delegación militar era ponerse al frente de la sublevación una vez que ésta hubiera estallado. Todo esto se hizo a espaldas del Ministerio de Estado, y para evitar que Arnao, al que se necesitaba para hacer gestiones ante la Residencia General francesa en Rabat, como la visita que Baraibar pretendía girar al General Noguès, éste utilizó su alto cargo, la credencial que tenía de Largo Caballero y el ofrecimiento de una promoción profesional de Arnao a la Embajada en Washington para que no informara a sus superiores de sus actividades. Se supone que Baraibar y Arnao visitaron al General Noguès, el 19 de abril, para informar y solicitar facilidades a las autoridades francesas del plan de sublevación, pero, de los breves informes disponibles que Baraibar remitió a Llopis sobre dicha visita, no se desprende que el tema ni siquiera se tocara. Tras estas disposiciones Baraibar regresó a Valencia y Dris el Riffi se instaló en Taza, una ciudad de la zona francesa próxima a la frontera con la española,

8 AMAE. RE. 40, 107, 2, 567-9 y 40, 107, 3, 610; Del Consulado General de España en Rabat al Ministro de Estado, 4-3-1937 (AMIAE. RE. 39, 101, 3, 362-7), y 10-3-1937 (AMAE. RE. 39, $100,6,342-3)$.

9 Citamos la cantidad máxima de dinero mencionada en la documentación; la mínima son tres millones trescientos mil francos (Araquistáin Papers, Leg. B. 30; en BolloteN, B., op. cit., pág. 710). En cualquier caso se trata de sumas fabulosas para la época; en Howson, G., op. cit., págs. $11,72,77,94,127,208$ y 211 ; se puede comprobar que daban para comprar varios bombarderos, cazas o tanques. 
para llevar a cabo los contactos y preparativos inminentes para desarrollar la misión ${ }^{10}$.

La primera actividad de Cazorla y el Riffi que consta es el intento, un tanto burdo, de utilizar al Cónsul en Uxda, José María Burgos, para sus planes, que comienzan a evidenciar una falta de claridad sospechosa de si sus verdaderas intenciones eran sublevar realmente las cabilas de la zona española. El citado cónsul había sido antes de la guerra civil interventor en la zona española, donde había hecho amistad con algunos marroquíes notables y por ello gozaba de cierto prestigio como especialista en los asuntos de la zona ${ }^{11}$. La segunda fue el intento culminado con éxito de acabar con la presencia en Marruecos del Vicecónsul adjunto en Rabat, Francisco Trujillo Arias. Arnao, persuadido a colaborar con la misión guardando silencio ante sus superiores, desconfiaba, no obstante, de los delegados, para los que dispuso un servicio de vigilancia a cargo del citado Trujillo. Los delegados lo descubrieron y urdieron un plan para que fuera llamado a Valencia y detenido. Para ello fue preciso engañar con informes falsos sobre las actividades de Trujillo en Marruecos al Subsecretario de Estado, Alfredo Nistal, que a finales de abril ejerció un protagonismo absoluto sobre estos acontecimientos, sin conocimiento directo del Ministro, y hábilmente manipulado por Baraibar. Cuando el 26 y el 27 de abril Trujillo fue requerido para presentarse en Valencia, producto de la mencionada trampa de los delegados para detenerle, Arnao decidió informar medidamente al Ministro de las dudas que le suscitaba la misión, de forma personal (todavía no oficial), aprovechando el viaje de aquél, para lo cual, además, había hecho discretas gestiones también personales para comprobar lo que sus superiores pudieran saber de su impropia actuación respecto a la misión ${ }^{12}$.

Coincidiendo en el tiempo con estos hechos, a finales de abril, se produjo la expulsión de Dris el Riffi de Taza, por orden de las autoridades francesas. Arnao se negó, sin autorización de sus superiores (el Ministro de Estado o el Embajador en París), a la petición de Cazorla de que solicitara de dichas autoridades francesas la anulación de tal expulsión. Baraibar pudo obtener de Nistal el curso de órdenes en tal sentido a Luis Araquistáin, hombre del círculo íntimo de Largo Caballero que conocía la misión, y al Cónsul General en Rabat, que pudo esperar a que aquél hi-

10 AMAE. RE. 40, 107, 2, 568, 575-8 y 581; AMAE. RE. 31, 159, 1; Del Consulado General de España en Rabat al Ministro de Estado, 12-5-1937 (AMAE. RE. 10, 41, 15, 172 y ss.), 28-5-1937 (AMAE. RE. 10, 41, 15, 180 y ss.), y 24-8-1937 (AMAE. RE. 16, 72, 7, 590 y ss.).

11 AMAE. RE. $40,107,2,577-8$ y 582 .

12 AMAE. RE. 40, 107, 2, 583-5, 593 y 599; AMAE. RE. 40, 107, 3, 608-9; Del Consulado General de España en Rabat al Ministro de Estado, 8-6-1937 (AMAE. RE. 10, 41, 15, 191). 
ciera gestiones en París, antes de hacerlas él en Rabat. El resultado, fueran cuales fueran tales gestiones sobre las que Araquistáin solo transmitió su impresión optimista, fue infructuoso, y Dris el Riffi solo fue autorizado a residir en Casablanca, lejos de la frontera interzonal, pues las autoridades francesas no estaban dispuestas a tolerar un levantamiento en la zona española que pudiera extenderse a la propia adquiriendo tintes nacionalistas. A pesar de ello, a principios de mayo, los delegados gubernamentales seguían manteniendo la viabilidad del proyecto ${ }^{13}$.

Por su parte, Arnao no se decidió a romper su silencio oficialmente hasta el momento en que fue llamado por el Ministro de Estado a Valencia, el 10 o el 11 de mayo, momento en el que realizó un largo informe de todo lo que sabía de la misión, desde sus inicios, omitiendo todo aquello que pudiera dejarle en mal lugar. En paralelo envió un informe del providencial ofrecimiento que le hacía en aquellos mismos momentos, a través del Cónsul en Fez, un marroquí notable para sublevarse, que permitía a los agentes consulares mostrar cuanto mejor manejaban ellos el asunto y le reconducían a fines más realistas, básicamente, en la línea del plan de agitación y sabotaje, más que de sublevación, de Antonio Pretel. Arnao se entrevistó con del Vayo el 14 de mayo, un día después de haberse desencadenado la crisis gubernamental que tenía en suspenso la continuidad del gabinete de Largo Caballero, quien en las conversaciones con Azaña para renovarle la confianza todavía esgrimió que el éxito de la misión en Marruecos, a pesar de que acababa de recibir un serio revés como hemos visto, podía cambiar el curso de la guerra. Pero, dado que no se le renovó la confianza, salió del Gobierno, y con él, todos los demás cargos con responsabilidad en la misión: Llopis, del Vayo, Nistal y Baraibar, que la daba nombre. Con la participación directa de éste la misión concluía con un rotundo fracaso y, sin embargo, los delegados por él nombrados obtendrían el beneplácito de las nuevas autoridades republicanas, en las condiciones que se verán, para persistir en el empeño ${ }^{14}$.

A finales del mes mayo ya se habían producido las primeras reacciones del nuevo Gobierno respecto a los delegados para la Misión Baraibar que quedaban en Casablanca y, a través del nuevo titular de Defensa, Indalecio Prieto, que asumía la antigua cartera de Guerra, se determinaba

13 AMAE. RE. 40, 107, 2, 579-80, 583, 596-7 y 601-3; Del Consulado General de España en Rabat al Ministro de Estado, 12-5-1937 (AMAE. RE. 10, 41, 15, 173).

14 Del Consulado General de España en Rabat al Ministro de Estado, 12-5-1937 (AMAE. RE. $10,41,15,173$ y $175-6$ y $5,12,7,92-4$ ), y 28-5-1937 (AMAE. RE. 10, 41, 15, 178 y 180); AMAE. RE. $40,107,2,587-8$. 
su continuidad, sin incurrir en nuevos gastos, con el solo propósito de sacar algún partido a los muy considerables que ya había hecho la anterior administración ${ }^{15}$.

A su regreso de Valencia, Arnao venía firmemente determinado a luchar por el fin de la delegación, poniendo al descubierto sus ineficaces actuaciones, su dispendio de dinero, y la imposibilidad de cumplir sus objetivos con la oposición de las autoridades francesas ${ }^{16}$. Cuando finalmente se enteró de la continuidad de la misión puso su cargo a disposición del Ministro y solicitó el traslado a una legación americana ${ }^{17}$, pero fue un momento de debilidad pasajera del que salió aún más determinado a conseguir sus objetivos, informando de la inoperancia a que se veían reducidos los delegados por la estrecha vigilancia a que les sometían las autoridades francesas ${ }^{18}$. Además, acentuó su estrategia de explotar los ideales ofrecimientos que hacían marroquíes dispuestos a sublevarse al Cónsul en Fez, a los que se unieron otros nuevos hipotéticamente hechos al Cónsul en Uxda, para desprestigiar a los delegados y su misión, y mostrarse como alternativa más viable para obtener resultados más realistas que una sublevación ${ }^{19}$.

Mientras tanto, los delegados de la Misión Baraibar seguían proclamando su convencimiento de que el levantamiento era inminente $y$, a fines de junio, el Riffi exigió como condición indispensable para su culminación que se obtuviera la autorización de las autoridades francesas para que le permitieran instalarse en Uxda por espacio de diez días, pues así se lo pedían sus contactos en la zona española. Era una petición muy sospechosa dado que las autoridades francesas ya le habían expulsado de la frontera interzonal (Taza) anteriormente. Paradójicamente, las maniobras de Arnao para que el Riffi fuera expulsado de Uxda, con la ayuda de los cónsules en Fez y Uxda (que se pueden descubrir en la alteración de las fechas de los informes que los tres realizaron sobre este episodio con el fin

15 De la Dirección General de Seguridad al Ministro de Estado, 22-5-1937 (AMAE. RE. 6, 15, 2, 321); Del Ministro de Estado al Cónsul de España en Casablanca, 29-5-1937 (AMAE. RE. 6, 15, 2, 325); Del Ministro de Defensa Nacional al [Ministro de] Estado, 1-10-1937 (AMAE. RE. 10, 41, $15,256)$.

${ }_{16}$ Del Consulado General de España en Rabat al Ministro de Estado, 28-5-1937 (AMAE. RE. 10, 41, 15, 178-82), 1-6-1937 (AMAE. RE. 10, 41, 15, 183-6).

17 Del Consulado General de España en Rabat al Ministro de Estado, 8-6-1937 (AMAE. RE. $10,41,15,189-192)$.

18 Del Consulado General de España en Rabat al Ministro de Estado, 18-6-1937 (AMAE. RE. $10,41,15,193-5)$.

19 Del Consulado General de España en Rabat al Ministro de Estado, 19-5-1937 (AMAE. RE. 5, 12, 7, 95-6), 6-6-1937 (AMAE. RE. 5, 12, 7, 104-6), 22-6-1937 (AMAE. RE. 7, 24, 13, 27-9), 256-1937 (AMAE. RE. 7, 24, 13, 30-1), 28-6-1937 (AMAE. RE. 7, 25, 7, 151-3). 
de encubrirlas), favorecieron los intereses de los delegados: escudarse en la oposición de las autoridades francesas para justificar su inoperancia y contraatacar acusando al Cónsul General y sus colaboradores de fascistas y de boicotear la misión. La escalada de la tensión entre agentes consulares y delegados a raíz de estos hechos alcanzó su punto culminante en el mes de julio ${ }^{20}$.

Esto determinó que, a principios de agosto, de acuerdo con el Ministro de Defensa, el Ministro de Estado, José Giral, enviara a Marruecos a dos altos funcionarios del departamento, el Secretario General, Luis Tobío Fernández, y el Secretario de la Sección de Información Diplomática Especial (SIDE), Valeriano Pastrana Peñamarín, para que le informaran de la actuación de los cónsules en relación con la mencionada comisión ${ }^{21}$. Además, poco después, se ordenó a todos los componentes de la delegación militar que se presentaran en Valencia. Por su parte, Arnao, enterado de la visita inminente de los funcionarios de su departamento, procedió a recopilar cuanta información pudo que desprestigiara a los delegados y a elaborar su versión de los hechos con la ayuda de sus colaboradores más estrechos, los cónsules en Fez, Uxda y Marrakech ${ }^{22}$. Salió así a relucir el caso del Comandante Cañivano, que daría lugar a un largo expediente jurídico, que finalmente resolvía que, tras su muerte a su regreso a Valencia, de los bienes que había adquirido en Agadir y el dinero que poseía, se hacía cargo la Presidencia del Consejo de Ministros y no su viuda e hijos ${ }^{23}$.

Pero la delegación civil al mando de Cazorla seguía contando con el respaldo de la más alta instancia gubernamental, la Presidencia del Consejo de Ministros, como transmitieron el Director General de Marruecos y Colonias, Argimiro Maestro de León, y el Subsecretario de la Presidencia, al Ministro de Estado, cuando éste solicitó una aclaración al respecto, a instancias de Arnao ${ }^{24}$.

20 AMAE. RE. 40, 107, 2, 587, 589 y 591-2; 40, 107, 3, 611-5; y 40, 107, 4, 628. Del Consulado General de España en Rabat al Ministro de Estado, 29-6-1937 (AMAE. RE. 8, 27, 14, 446-8), 7-7-1937 (AMAE. RE. 8, 30, 13, 823-6), 10-7-1937 (AMAE. RE. 40, 105, 2, 455-6), 12-7-1937 (AMAE. RE. 10, 41, 15, 198-200), y 15-7-1937 (AMAE. RE. 8, 29, 14, 691-2).

21 Del Gabinete Político (Información) al Ministro de la Gobernación, 5-8-1937 (AMAE. RE. 10, $41,15,205-6)$.

22 Del Consulado General de España en Rabat al Ministro de Estado, 20-8-1937 (AMAE. RE 16, 72, 7, 588-9), 23-8-1937 (AMAE. RE. 10, 41, 15, 207-20).

23 Del Consulado General de España en Rabat al Ministro de Estado, 24-8-1937 (AMAE. RE. 16, 72, 7, 590-5). Expediente jurídico citado en AMAE. RE. 16, 72, 7, 602-45.

24 De la Presidencia del Consejo de Ministros (Dirección General de Marruecos y Colonias) al Ministro de Estado, 1-9-1937 (AMAE. RE. 10, 41, 15, 213). De la Presidencia del Consejo de Ministros (Subsecretaría) al Ministro de Estado, 14-9-1937 (AMAE. RE 16, 70, 5, 240). 
Sólo la inopinada intervención de las autoridades francesas, a finales de septiembre, proporcionó argumentos convincentes a Arnao para acabar con los últimos vestigios de la Misión Baraibar. Aquéllas denunciaron ante el Cónsul General que Dris el Riffi estaba trabajando con los nacionalistas marroquíes, apoyados por los rebeldes, en actividades que perjudicaban a ambos gobiernos, y solicitaban un mentís del Gobierno republicano en el sentido de que el citado marroquí estuviera recibiendo fondos que pudiera emplear en dichas actividades. Fue necesaria incluso la visita a las autoridades francesas en Rabat del Director General de Marruecos y Colonias, para dar fuerza al mentís español. Pocos días después, Cazorla resultaba implicado en dicha trama, acusado por las autoridades francesas de haber informado al Riffi de la acusación que pesaba sobre él, lo que obligó a nuevas explicaciones oficiales españolas que tardaron en llegar ${ }^{25}$.

Porque en el ínterin, ya a mediados de octubre, los citados Tobío y Pastrana habían concluido su informe (que exoneraba a las autoridades consulares de la acusación de boicotear la Misión Baraibar, aunque haciendo constar el impropio proceder de Arnao con sus superiores, y juzgaba, en cambio, a los delegados y a la labor realizada muy duramente), que se entregó al Director General de Marruecos y Colonias junto con una copia del informe de Arnao sobre las denuncias de las autoridades francesas contra Cazorla. Rápidamente se dispuso que se enviaran a Marruecos la orden a Cazorla de presentarse en Valencia y las aclaraciones oficiales pedidas por la Residencia General francesa; pero éstas no llegaron al Ministerio de Estado hasta finales de mes, en que pudieron ser remitidas al Cónsul General en Rabat ${ }^{26}$.

Cazorla se negó a cumplir la orden de presentarse en Valencia y siguió en Marruecos. Arnao continuó informando de sus dudosas actividades para encubrir su actuación en la misión y solicitó confirmación sobre si seguía ostentando la condición de delegado gubernamental. No consta que recibiera tal aclaración, pero cabe suponer que la Misión Baraibar había concluido definitivamente, sin que, como había pretendido Prieto,

25 Del Consulado General de España en Rabat al Ministro de Estado, 23-9-1937 (AMAE. RE. 16, 72, 3, 547-9), 30-9-1937 (AMAE. RE. 16, 72, 3, 558) y 4-10-1937 (AMAE. RE. 10, 41, 15, 262-4).

${ }_{26}$ Del Gabinete Político (Información) al Presidente del Consejo de Ministros (Marruecos y Colonias), 17-10-1937 (AMAE. RE. 10, 41, 15, 268). Conclusiones del informe en AMAE. RE. 40, 107, 4, 621-8. De la Presidencia del Gobierno (Dirección General de Marruecos y Colonias) al Ministro de Estado, 18-10-1937 (AMAE. RE. 10, 41, 15, 269). De Anselmo Carretero a Argimiro Maestro de León, 29-10-1937 (AMAE. RE. 10, 41, 15, 274-5). Del Ministro de Estado al Cónsul General de España en Rabat, 29-10-1937 (AMAE. RE. 10, 41, 15, 271). 
se sacara ningún provecho visible de su continuidad, que mitigara su rotundo fracaso inicial ${ }^{27}$.

\section{HIPÓTESIS: UN INTENTO DE LARGO CABALLERO DE PERMANECER EN EL GOBIERNO}

Como anticipé, interpreto conjeturalmente estos hechos en clave fundamentalmente política, en el contexto del enfrentamiento entre comunistas y caballeristas en el seno gubernamental.

Sólo así puedo razonablemente explicar la decisión del propio Largo Caballero, según las fuentes citadas, de desestimar el plan comunista de agitación y sabotajes, que contaba con la aquiescencia de los agentes consulares, por otro menos realista de provocar una sublevación de las cabilas de la zona española, extraordinariamente dotado de fondos, con responsables específicos de su absoluta confianza y observado con reticencia por los agentes consulares.

La primera visita de Baraibar a Marruecos, para recoger información sobre el terreno para realizar los preparativos de la misión, coincidió con el recrudecimiento de la pugna política entre comunistas y caballeristas tras la caída de Málaga el 8 de febrero. Las presiones de los primeros obligaron a Largo Caballero a cesar a un hombre de su entera confianza, el General Asensio (precisamente sustituido por Baraibar), forzando extraordinariamente su voluntad, lo que le produjo un notable malestar. Además, aquéllos utilizaron incluso al embajador soviético, lo que provocó un muy comentado incidente en el que Largo Caballero le expulsó de su despacho, junto con su Ministro de Estado, Álvarez del Vayo, que le acompañaba, y al que luego acusaría de traidor, por servir a los intereses comunistas después de haber pertenecido a su círculo de confianza.

Todo ello pudo determinar que cuando Baraibar volvió a Marruecos a mediados de abril, para hacer las últimas disposiciones del plan de sublevación de las cabilas, fuera decidido a neutralizar las reticencias del Cónsul General en Rabat y los problemas que pudiera generar el que éste informara a su superior, el Ministro de Estado Álvarez del Vayo, convencidos de que se trataba de un agente comunista que podría boicotear sus pla-

27 Del Consulado General de España en Rabat al Ministro de Estado, 30-10-1937 (AMAE. RE. 10, 41, 15, 276), y 10-11-1937 (AMAE. RE. 10, 41, 15, 232-4). Del Gabinete Político (Información) al Presidente del Consejo de Ministros (Dirección General de Marruecos y Colonias), 20-11-1937 (AMAE. RE. 10, 41, 15, 278). 
nes. La necesaria cobertura derivada de su actuación en el exterior procedía del embajador en París, Luis Araquistáin, prestigiosa figura política y totalmente fiel a Largo Caballero.

Baraibar, valiéndose de su cargo y del respaldo a su misión del Presidente del Consejo de Ministros, y tentando a Arnao con un ascenso a la Embajada en Washington, le involucró en la misión y consiguió que no informara a sus superiores, faltando flagrantemente a las obligaciones de su cargo.

Tras visitar al Residente General francés, General Noguès, en compañía de Arnao, Baraibar abandonó Marruecos de nuevo y dejó al cargo de la dirección de una amplia delegación a Cazorla.

Los detalles de esta misión se presentan tan oscuros, que hacen dudar de que sus verdaderas intenciones fueran las apuntadas. En primer lugar, todo apunta a que las autoridades francesas no estaban dispuestas a tolerar que desde territorio bajo su jurisdicción se fomentara una sublevación de las cabilas de la zona española: primero, por temor a que tal sublevación pudiera alentar las aspiraciones de los nacionalistas marroquíes, activos en su zona y que estaban en buenos términos con los rebeldes, los germanos y los italianos, que fomentaban medidamente sus reivindicaciones para crear dificultades a Francia; y segundo, porque ésta misma, obligada a seguir la política británica de apaciguamiento del fascismo, evitaba a toda costa cualquier gesto que pudiera ser interpretado por Alemania como una provocación (y desde luego lo era apoyar una iniciativa contra Franco al que era notorio que Hitler y Mussolini apoyaban) ${ }^{28}$. Son inexplicables, en este contexto, las gestiones que los delegados gubernamentales pretendían hacer ante las autoridades francesas para facilitar la $\mathrm{Mi}$ sión Baraibar, empezando por las de éste mismo ante el General Noguès. De hecho, cuando se dispone de algún informe de lo tratado, no queda nada claro que se tocara el tema de la sublevación y, en cualquier caso, los hechos posteriores desmentían invariablemente cualquier facilidad que las autoridades francesas hubieran hipotéticamente comprometido. Véase, por ejemplo, la expulsión de Dris el Riffi de Taza, en la frontera interzonal hispano-francesa, donde era lógico que se acercara para mantener contactos con emisarios de la zona española para preparar la sublevación.

En segundo lugar, constituye otro elemento oscuro de la misión la destacada participación en ella del propio el Riffi, como marroquí de prestigio para fomentar la adhesión de elementos a la sublevación, cuando todos,

28 Al.PERT, M., op. cit., pág. 132. 
sin excepción, los testimonios recogidos sobre su persona, próximos a los hechos y más lejanos, le califican como una persona totalmente desacreditada, no solo entre los marroquíes, lo que es clave, sino entre los españoles (a unos y a otros traicionó alternativamente a lo largo de su vida), y también entre los franceses. Que, además de todo esto, se le adelantara una cantidad exorbitante de dinero por dicha participación, contribuye a oscurecer más la Misión Baraibar.

Tercer aspecto oscuro de ésta; que este despliegue de medios económicos y humanos se frustrara por el solo hecho de que Dris el Riffi fuera expulsado de Taza por las autoridades francesas. En este sentido, hay que considerar la presencia de un Subsecretario de la Guerra y la disposición de varios jefes y oficiales militares en plenas campaña del Norte y Batalla de Brunete; la entrega de Dris el Riffi a una vida plena de lujos y sus sospechosos comportamientos en relación con la misión, como la comedia que organizó con Cazorla para captar o utilizar al Cónsul en Uxda, José María Burgos.

$\mathrm{Y}$, cuarto, que, no obstante todo esto, se siguiera defendiendo en círculos gubernamentales que la sublevación era inminente, hasta el punto de que Largo Caballero, en plena crisis gubernamental para renovarle la confianza, lo esgrimió ante el Presidente de la República, añadiendo que, de producirse con éxito, cambiaría el curso de la guerra a favor del Gobierno.

La única explicación, hipotética por carecer de fuentes en que apoyarme para afirmarlo, que encuentro para conjugar hechos tan contradictorios es que, en medio del enfrentamiento con los comunistas, cuando adquirió su perfil más nítido de lucha abierta por el poder, Largo jugó la baza de la sublevación de las cabilas como un argumento desesperado para su mantenimiento en el Gobierno, aunque detrás del mismo no había realmente nada, sólo una comedia.

Así, las gestiones con las autoridades francesas no se explicitan nunca, porque no se hablaba nada de un plan que se sabía que aquéllas desaprobaban, pero había que fingir que se hacían para mantener la ficción.

Nadie mejor que el desacreditado Dris el Riffi para prestarse a un engaño de esta naturaleza, con el único inconveniente de que cobró un precio abusivo, aunque el dinero no parecía ser un problema.

Así, tampoco extraña que el resto de los delegados no mostraran la menor reticencia a creer y colaborar en todas las maniobras del citado marroquí. Ni que en un ambiente tan relajado el Comandante Cañivano llegara a confundir lo público con lo privado, adquiriendo propiedades con el dinero destinado a la misión. 
El Cónsul General en Rabat sí que se dio cuenta de estos manejos, y al parecer enseguida, pero ya estaba atrapado en su trama, porque también se había dejado sobornar, con una promoción profesional, y porque había incumplido sus funciones consulares al no informar en tiempo y forma a sus superiores. Además, tenía que soportar el menoscabo de sus competencias y las dificultades para su desarrollo que se pudieran derivar de una actuación tan irregular en su jurisdicción. Tenía que denunciarlo, pero con extraordinaria cautela para ocultar su impropio proceder.

La vigilancia de los delegados que dispuso para enterarse de sus manejos, pronto fue descubierta, y su artífice, su Cónsul adjunto Francisco Trujillo Arias, un hombre que no era diplomático y de pasado un tanto turbio, pagó las consecuencias con una detención arbitraria urdida por Baraibar y los delegados. Baraibar consiguió ganarse con subterfugios al Subsecretario de Estado, Alfredo Nistal, que a fines de abril gozó de un protagonismo absoluto en el Ministerio respecto a este asunto, pues del Vayo, en nombre de quien se remitían instrucciones al respecto, todavía no estaba enterado realmente.

Aprovechando el viaje de Trujillo a Valencia, que los delegados habían urdido para detenerle, Arnao envió un informe personal para del Vayo donde empezaba a desentrañar muy cautamente la trama de la misión y las dudas que le generaba. Para ello había hecho previamente discretas gestiones para comprobar que sus superiores no estaban informados de su actuación en la misma, porque era consciente de que los delegados podían esgrimir el censurable silencio que había guardado con ellos.

Además, Arnao no informó oficialmente de la Misión Baraibar al Ministro de Estado hasta que éste no le convocó a Valencia, inmediatamente antes de desencadenarse la crisis del Gobierno de Largo Caballero. En paralelo inició, con la ayuda de sus colaboradores más fieles, los cónsules en Fez, Luis Monguió Primatesta, Uxda, el citado Burgos, y Marrakech, Antonio Ayala Hernández, una campaña para desacreditar a los delegados. Consistió en promover, como si fuera espontánea, una serie de ofrecimientos de marroquíes de la zona española para sublevarse, que le serviría durante muchos meses para el objetivo señalado de desacreditar a los delegados y su misión, y al complementario de que si dicha misión, no obstante, debía realizarse, los agentes consulares eran los actores más indicados.

La entrevista celebrada con del Vayo, en la que éste finalmente tuvo algún conocimiento de lo que sucedía con la Misión Baraibar, no tuvo ninguna trascendencia tras la renovación del Gobierno, por la que los actores principales de la misión, Baraibar que la da nombre en primer lugar, de- 
saparecieron de la escena política. El nuevo Ministro de Defensa Nacional, Indalecio Prieto, tomó la iniciativa de dar continuidad a la misión, manteniendo en sus puestos a Cazorla, a Dris el Riffi, y a los delegados militares, pero sin incurrir en nuevos gastos y con el único propósito de intentar sacar partido a los extraordinariamente abultados que ya se habian hecho.

Arnao, liberado en gran parte de las circunstancias que le constreñían, al ser las personas y las líneas políticas del nuevo Gobierno diferentes a las del anterior, intensificó su campaña contra la delegación, urdiendo artimañas más atrevidas, como la expulsión de Dris de Uxda.

Aunque sobre las maniobras que intentaron los delegados (como ésta del Riffi de intentar volver a instalarse en la frontera interzonal, cuando las autoridades francesas ya le habían expulsado anteriormente), recae la sospecha de que eran desesperados intentos de justificar ante los nuevos responsables políticos el soborno y el encargo de una misión ficticia que habían recibido de unos altos cargos que ya no podían encubrirles.

En la guerra que se desencadenó entre delegados y agentes consulares, estos recibieron el refuerzo de la investigación de los altos funcionarios de su Ministerio, que, con la aquiescencia de Prieto, fueron a investigar las relaciones entre ambos grupos irreconciliables. Aunque censuraron el silencio de Arnao, exoneraron a los agentes consulares que éste encabezaba de la acusación de los delegados de boicotear su misión, que juzgaron en términos muy duros.

La poca simpatía de que gozaba el Riffi entre las autoridades francesas y el accidentado trámite de los últimos informes disponibles de la misión, abonan la hipótesis (que, no obstante, habría que conjugar con el traslado del Gobierno a Barcelona entre octubre y noviembre, y que los informes de Arnao sean la única fuente disponible) de una conjunción entre autoridades francesas y agentes consulares para acabar con los restos de la Misión Baraibar.

Coincidiendo con el final de la investigación de Tobío y Pastrana, las autoridades francesas denunciaron a las españolas que Dris el Riffi había empleado el dinero recibido para la misión en contribuir a la agitación nacionalista marroquí contra los intereses de ambos gobiernos. Poco después Cazorla resultaba implicado en esta trama, acusado por las mismas autoridades francesas de haber informado al citado marroquí de que sobre él pesaba tal acusación. Estos incidentes con las autoridades francesas determinaron finalmente a la Presidencia del Consejo de Ministros y al Ministerio de Defensa a ordenar la presencia de Cazorla en Valencia, que no consta que éste cumpliera, pero que se supone puso fin a la Misión Baraibar. 